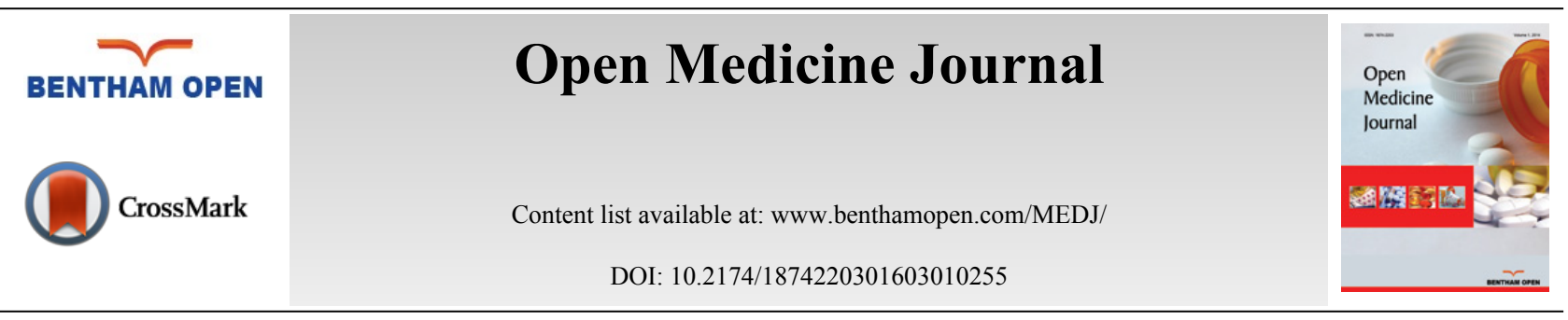

REVIEW ARTICLE

\title{
Pharmacological Management of Post-thoracotomy Pain
}

\author{
Joel Wann Ee Chin ${ }^{1}$ and Kamen Valchanov ${ }^{2, *}$ \\ ${ }^{\prime}$ Addenbrooke's Hospital NHS Trust, Hills Road, Cambridge, CB2 0QQ, United Kingdom \\ ${ }^{2}$ Papworth Hospital NHS Trust, Papworth Everard, Cambridge, CB23 3RE, United Kingdom
}

Received: August 05, 2016

Revised: October 14, 2016

Accepted: November 10, 2016

\begin{abstract}
Thoracotomy is widely recognised as one of the most painful surgical procedures. The combination of extensive tissue dissection and dynamic respiratory movement postoperatively makes post-thoracotomy pain control particularly challenging. In the short term, inadequate analgesia is associated with respiratory complications, poor mobilisation, delayed discharge and respiratory infections. More importantly, poorly controlled postoperative pain is associated with developing chronic post-thoracotomy pain, also known as post-thoracotomy pain syndrome (PTPS). The reported incidence is between $25-60 \%$ and can be debilitating and difficult to treat. Increasing understanding of complex nociceptive pathways and neuropathic mechanisms has generated interest in the use of new therapeutic agents termed as adjuncts to post-operative opioid analgesia. In the area of thoracic surgery, the use of analgesic adjuncts has been subjected to a number of studies in recent years. In this article, we present a literature review of current treatment strategies for management of post-thoracotomy pain with evidence of effectiveness.
\end{abstract}

Keywords: Analgesic adjuncts, Chronic pain, Multimodal analgesia, Post-thoracotomy pain.

\section{INTRODUCTION}

Thoracotomy involves high-intensity noxious stimuli due to extensive tissue damage and inflammation [1]. Difficult access to lung means that one or more ribs are subjected to resection and retraction with damage to intercostal muscles, nerves and costovertebral joints. Although the modern thoracic surgery relies extensively on ports for the thoracoscopic approach, these can still produce tissue damage and nerve damage. Pain from tissue injury is exacerbated by the dynamic motion of breathing after surgery and the presence of intercostal drains irritating the pleura. Bearing in mind that patients undergoing thoracotomy often have serious underlying pathology with limited pulmonary reserves, inadequate pain control can have serious consequences. Limited inspiration due to pain impairs the mechanics of ventilation resulting in pulmonary shunting and hypoxia [1]. Additionally, the inability to take a deep breath also causes ineffective coughing and retention of secretions. This leads to mucus retention, plugging, atelectasis and pneumonia [2]. Aside from respiratory complications, there is an increased risk of nosocomial infections, delayed recovery and discharge. Furthermore, there is emerging evidence that severe acute pain is associated with increased risk of PTPS [3]. The burden of PTPS is increasingly being recognised. In one study, 70\% of patients required three or more treatment modalities, $50 \%$ were referred to three different specialties and none reported to be symptom free [4]. However, the advances of pain management in recent years have seen the introduction of newer agents that are aimed at novel targets along the nociceptive pathway. There has been relative success seen in other chronic pain conditions resulting in its introduction to thoracic surgery [5].

\section{ACUTE PAIN}

Despite years of advances in pain management, the mainstay of postoperative pain therapy in many settings is still opioids [6]. However, their use is limited by side effects. Nausea, constipation and sedation are common side effects

\footnotetext{
* Address correspondence to this author at the Papworth Hospital NHS Trust, Papworth Everard, Cambridge, CB23 3RE, United Kingdom; Tel: +441480830541: E-mail: kamen.valchanov@nhs.net
} 
that contribute to poor post-operative recovery. More importantly, opioid-induced respiratory depression exacerbates the problems of pulmonary complications following thoracotomy surgery. Hence, systemic opioids are best used as part of a multimodal analgesic strategy that includes regional local anaesthetic and non-opioid analgesia.

There are numerous multimodal analgesic techniques and regimens used in practice. Typically, regional analgesia is instituted pre or intraoperatively and continued postoperatively either as an infusion or patient controlled analgesia system delivered through a catheter placed in situ - in the thoracic epidural or paravertebral space [7]. Regular paracetamol and non-steroidal anti-inflammatory drugs (NSAIDs), if not contraindicated, are initiated immediately after surgery. Patient controlled opioid administration can be used to supplement regional analgesia. For simplicity, a fixed epidural or paravertebral local anaesthetic infusion can be complemented by a patient controlled intravenous infusion of opioids that is limited by demand dose only for safety. This allows for a smooth transition to oral analgesia when demand dose requirements are reduced [7].

While the combination of local anaesthetic and opioid analgesia is generally effective, it is far from perfect. Issues of poor ipsilateral shoulder pain cover [8], variable success rates of regional techniques and side effects of systemic opioids have prompted the search for adjuncts to be included in the armamentarium. Numerous trials have been conducted for ketamine, gabapentinoids, dexmedetomidine, clonidine and magnesium. Results of these studies have generally been positive. A best evidence topic reviewing five clinical trials with 243 patients undergoing thoracic surgery found that adding ketamine to patient controlled morphine significantly reduced pain scores and opioid requirements on day 3-4 postoperatively with no hallucinations or psychological side effects [9]. Another best evidence topic looking at gabapentin found that multi-doses perioperatively was safe and beneficial in reducing acute pain [10]. However, the caveat for these studies is that they are often small and generally underpowered. More clinical trials are required for a meta-analysis in order to properly assess their efficacy and side effect profile in post-thoracotomy patients. Hence, the use of these agents is not as widespread and often limited to rescue analgesia when conventional strategies have failed.

\section{CHRONIC PAIN/POST-THORACOTOMY PAIN SYNDROME (PTPS)}

Patients are at risk of developing pain that persists beyond the initial recovery following thoracotomy. The International Association for the Study of Pain (IASP) defines it as 'pain that recurs or persists along a thoracotomy scar at least 2 months following surgical procedure' [1]. The reported incidence is between 20-60\% [7], with most cases experiencing mild pain at 3 months, which eventually wears off [11]. However, for the minority with persistent pain, the effects can result in severe physical and functional impairment.

The underlying mechanism and transition to developing PTPS are not well understood. Factors related to patients, surgical approach, perioperative timing and psychosocial elements have been studied without any conclusive findings. This may be partly due to studies being heterogeneous and underpowered [12]. However, the role of intercostal nerve injury appears to be the most consistent factor in contributing to PTPS. This is further strengthened by the association of prolonged intercostal chest drain duration [13], again with the putative mechanism of intercostal nerve injury being the cause [14]. However, this is counteracted by the fact that video-assisted thoracoscopic procedures have not been shown to reduce the incidence of PTPS compared to thoracotomies, despite the former causing less trauma to nerves [1].

Neuropathic pain is defined as pain that results from injury or dysfunction to the somatosensory system [15]. The current understanding of neuropathic pain is an extension of Melzack and Wall's 'gate theory', which involves spatial (peripheral and central pathways), chemical (inflammatory mediators and ion channels) and neuronal interactions (sensitisation, wind up and disinhibition) [16]. In thoracotomy, inflammation at nociceptive sites leads to electrical conduction along pain fibres to the spinal cord and higher cortical areas. Chronic pain develops when there is spontaneous firing of neurotransmission despite tissue healing and cessation of nociceptive input [17]. Damaged intercostal nerves become foci of ectopic discharges. Chemical mediators such as calcitonin gene related peptide and substance $\mathrm{P}$ are released during inflammation together with by-products such as prostaglandin, histamine and cytokines, which reduce the firing thresholds for ectopic discharges. Furthermore, there is upregulation of sodium, calcium and potassium channels at the site of injured nerves and dorsal root ganglion, which increases excitation in an established spontaneous conduction pathway [18]. At the spinal level, there is a complex interplay of excitatory neurotransmitters and intracellular signalling cascades which lead to 'wind up' - a phenomenon where C fibres are repetitively activated causing increased frequency and magnitude of dorsal root ganglion firing [19]. Finally, disinhibition occurs at both peripheral and central conduction points due to increased chloride ion conduction at nerve terminals [20], downregulation of opioid $\mu$-receptors and apoptosis of inhibitory interneurons [16]. 
This model of understanding is helpful in that it provides a blueprint for targeting therapy, but it also partially explains why neuropathic pain is not straightforward to treat given its multi-level complexity. Not only is complete afferent impulse blockade difficult to achieve, but also 'humoral blockade' involving a myriad of inflammatory markers is challenging [1]. Nonetheless, this has engendered the emergence of adjunct therapies that target calcium channels, Nmethyl-D-aspartate (NMDA) receptors and sodium receptors in the neuropathic pain pathway. While demonstrating relative benefit in other chronic pain conditions, these novel therapies have started to be employed in managing PTPS.

\section{PHARMACOLOGICAL PREVENTION STRATEGIES FOR PTPS}

Given that central sensitisation underlies the development of chronic pain, there has been a lot of interest in prevention of PTPS by attenuating the nociceptive response of acute pain. In fact, the risk of chronic pain has been consistently associated with the severity of acute postoperative pain [3]. Even the presence of neuropathic pain immediately in the postoperative period has been suggested as a predictor of PTPS due to its strong association [21]. Hence, effective analgesic management of PTPS should commence before surgical incision has taken place.

Pre-emptive thoracic epidural analgesia should theoretically target the process of central sensitisation and reduce the inflammatory mediators in the nociceptive pathway. However, studies have not clearly demonstrated a reduction in PTPS [1]. Given the complex mechanism of the development of PTPS, a multimodal pharmacological strategy perioperatively is recommended in pre-empting chronic pain.

\subsection{Gabapentinoids}

Gabapentinoids are 3-substituted derivatives of the neurotransmitter $\gamma$-aminobutyric acid (GABA), which block $\alpha 2 \delta$ subunit-containing voltage-dependent calcium channels (VDCCs), which are present on presynaptic terminals. Initially designed as anticonvulsive drugs, gabapentinoids have been shown to have analgesic properties, probably due the presence of VDCCs at the nociceptive pain pathway. A combined systematic review and meta-analysis revealed that perioperative administration of gabapentin and pregabalin is effective in reducing the incidence of chronic postsurgical pain [22]. However, the clinical heterogeneity is considerable in these trials. Surgical procedures were mainly orthopaedic, abdominal and gynaecological and the dosing regimen of gabapentin varied widely.

The evidence for post-thoracotomy pain is limited. A best evidence paper of preoperative administration of gabapentin, which included three randomised control trials failed to observe a statistically significant effect in postthoracotomy patients [10]. However, two prospective trials demonstrated significant pain reduction at two months when gabapentin was continued daily until two months after surgery [10]. When extended to only five days post surgery, a Danish study failed to detect a difference at six months [23]. Perhaps these studies suggest that gabapentin is better used as treatment for established neuropathic pain instead of pre-emptive analgesia. This is supported by a prospective study of patients on long-term daily gabapentin where $73 \%$ of patients had reduced pain and paraesthesia even after two years [24].

Pregabalin is another structural analogue of GABA similar to gabapentin and has the same mechanism of action. It comes with the added benefit of a simpler dosing and titration regime compared to the latter [25]. Studies looking at the use of pregabalin in PTPS have been small with varied results. The largest study of ninety-nine patients in fact demonstrated an increase in PTPS [26], which suggests that larger trials are needed to accurately determine its effectiveness despite the positive results of a few studies [27].

\subsection{Ketamine}

Ketamine is a phencyclidine derivative and is the most potent clinically available, uncompetitive, open-channel NMDA-receptor blocker [28]. Its profound analgesic effect is well documented and has been extended from perioperative use to management of chronic pain and palliative therapy. Concerns of adverse side effects are mitigated by careful dose titration and follow up.

There have been more trials on ketamine in PTPS compared to other adjunctive therapies. There is good evidence that it reduces acute pain [29], but its use in pre-emptive analgesia for chronic pain cannot be recommended. In several randomised controlled trials that had preoperative bolus with continuous intravenous infusion of ketamine, none has demonstrated any reduction in pain after the acute phase [30 - 32]. Moreover, the use of the S+ isomer of ketamine, which is associated with higher potency and fewer side effects, has not shown any difference either [33]. 


\subsection{Non-steroidal Anti-inflammatory Drugs (NSAIDs)}

Pre-emptive analgesia should include targeting inflammatory mediators, which increase peripheral sensitisation. Prostaglandins can be reduced by cyclooxygenase inhibitors. In a small randomised controlled trial, the addition of pre and post surgical intravenous dexketoprofen to thoracic epidural analgesia resulted in a significant difference in reducing chronic pain [34]. However, there is a paucity of trials assessing the effect of NSAIDs on chronic pain to confirm this result.

Other studies have looked at the role of cylooxygenase (COX)-2 selective inhibitors. The inducible form of the enzyme - COX-2 is responsible for inflammation and pain. The selective inhibition of COX-2 enzymes reduces the risk of adverse gastrointestinal side effects associated with NSAIDs. In a randomised trial, thirty patients undergoing thoracotomy had their cerebrospinal fluid (CSF) sampled for 6-keto-PGF1 $\alpha$, the principle metabolite of prostacyclin [35]. They were randomised to receive either a COX-2 specific inhibitor or a non-selective inhibitor alongside a control group. Mean 6-keto-PF1 $\alpha$ levels in CSF increased following surgery and when suppressed by the COX-2 specific inhibitor group but not by the non-selective inhibitor group. Pain scores and morphine requirements were significantly lower in the former as well. COX-2 selective inhibitors were popular when they emerged on the market, but safety concerns due to increased cardiovascular problems have led to the withdrawal of some of the drugs with the remaining ones being under close monitoring [36].

\subsection{Other Adjuncts for Neuropathic Pain}

There is very limited research into other adjunctive therapies in preventive analgesia of PTPS. Clonidine, dexmedetomidine and magnesium have been used in treating other chronic pain conditions but their use in PTPS is debatable even in treating acute pain [37 - 39]. From an anaesthetic perspective, there has been a single study comparing total intravenous anaesthesia (propofol and remifentanil combination) and inhalational (sevoflurane) anaesthesia, which showed the former having a significant pain reduction even at 3 and 6 months post surgery [40]. The postulated reason is that volatile agents may induce a hyperalgesic state mediated by nicotinic inhibition [41]. However the inhalational group in this study used sevoflurane as a sole anaesthetic agent, which meant that remifentanil infusion might have been a confounding factor. Although no studies have examined the use of remifentanil in reducing PTPS, one study demonstrated that substituting epidural analgesia before surgery with high dose remifentanil is associated with a higher incidence of chronic pain and a larger area of allodynia [42].

\section{5. $\beta 2$-Adrenoreceptors - a Novel Target}

There is emerging experimental data on murine model of neuropathic pain that $\beta 2$-adrenoreceptors are essential for the antiallodynic action of antidepressants [43]. A case series of six patients with chronic back pain reported significant pain reduction after regular use of salbutamol for a month [44]. This prompted an epidemiological study into its use in post-thoracotomy patients, which revealed that chronic use of $\beta 2$ agonists was associated with a five-fold decrease in the relative incidence of neuropathic pain [45]. However, there have been no published prospective trials to date.

Table 1. Summary of analgesic adjuncts for post-thoracotomy pain in terms of benefit and strength of evidence. Classification of evidence based on National Guideline Clearinghouse ${ }^{\mathrm{TM}}$ /Agency for Healthcare Research and Quality (AHRQ).

\begin{tabular}{|c|c|c|}
\hline Analgesic adjunct & Benefits & Evidence \\
\hline Gabapentinoids & $\begin{array}{c}\text { Acute pain and } \\
\text { chronic neuropathic pain } \\
\text { No evidence for pre-emptive analgesia }\end{array}$ & $\begin{array}{l}\text { Ib for acute pain, } \\
\text { Ia for chronic neuropathic pain }\end{array}$ \\
\hline Ketamine & $\begin{array}{c}\text { Acute pain } \\
\text { No evidence of pre-emptive analgesia }\end{array}$ & $\mathrm{Ib}$ \\
\hline NSAIDs & $\begin{array}{l}\text { Acute pain and } \\
\text { pre-emptive analgesia }\end{array}$ & $\begin{array}{c}\text { Ib for acute pain, } \\
\text { Ib (weak evidence) for pre-emptive } \\
\text { analgesia }\end{array}$ \\
\hline Magnesium & - & - \\
\hline Clonidine/dexmedetomidine & - & - \\
\hline$\beta 2$-agonist & Chronic neuropathic pain & III \\
\hline Anti-depressants - TCA, SNRI & Chronic neuropathic pain & Ia \\
\hline Topical lidocaine & Chronic neuropathic pain & $\mathrm{Ib}$ (weak evidence) \\
\hline Topical capsaicin & $\begin{array}{c}\text { Chronic neuropathic pain (especially post-herpetic neuralgia and HIV- } \\
\text { neuropathy) }\end{array}$ & $\mathrm{Ib}$ \\
\hline
\end{tabular}




\section{PHARMACOLOGICAL TREATMENT FOR ESTABLISHED PTPS}

Established post-thoracotomy pain is managed using the same strategies for treating neuropathic pain. This is based on recent recognition of neuropathic pain being a specific entity across neuropathic syndromes [46] and the efficacy of systemic drug therapy being independent of aetiology [47]. Pharmacological therapies for neuropathic pain include antidepressants e.g.: tricyclic antidepressants (TCA) and serotonin-norepinephrine reuptake inhibitors (SNRI), anticonvulsants e.g.: gabapentinoids, carbamazepine, lamotrigine, and topical lidocaine or capsaicin (Table 1).

\subsection{Antidepressants}

The role of antidepressants in relieving neuropathic pain was recognised as early as 1982 [48]. Tricyclic antidepressants like amitriptyline in particular had good results in treating diabetic neuropathy and post-herpetic neuralgia [49]. The anti-neuralgic effect is independent of its antidepressant properties, as their analgesic action is consistent in both patients with and without depression. The putative mechanism of action is the inhibition of serotonin and norepinephrine reuptake in the descending inhibitory fibres along the pain pathway. In essence, they enhance inhibitory signals from brainstem to the spinal cord and limit the transmission of pain stimulus to the brain.

Newer agents have emerged which are more selective in inhibiting monoamine reuptake and are classed as SNRIs. Of these drugs, only duloxetine and venlafaxine have relatively good data supporting their use for neuropathic pain [50]. They have the benefit of producing fewer side effects compared to amitriptyline.

\subsection{Anticonvulsants}

The first anticonvulsant properly studied in clinical trials for neuropathic pain is carbamazepine, which remains popular as first line treatment for trigeminal neuralgia. Gabapentinoids have generated a lot of interest with a total of at least fourteen high quality randomised controlled trials for gabapentin and twenty-five for pregabalin by 2015 [50]. Approximately two-thirds of these trials were positive with a derived Numbers Needed to Treat (NNT) of 6.3 (5-8.3) for gabapentin and 7.7 (6.5-9.4) for pregabalin. Most studies using other anti-epileptics were negative. Anti-epileptics are thought to work in a number of different ways in neuropathic pain. The older antiepileptics like carbamazepine and phenytoin probably reduces sodium channel conductance along the path pathway, whereas gabapentinoids block $\alpha 2 \delta$ subunit-containing voltage-dependent calcium channels (VDCCs), which are upregulated in experimental pain models $[51]$.

\subsection{Topical Local Anaesthetic}

The use of lidocaine patches and gels in varying concentrations have been trialled for neuropathic pain with limited success. A Cochrane review found no evidence from good quality randomised controlled studies to support the use of topical lidocaine to treat neuropathic pain, although individual studies indicated that it was effective for relief of pain [52]. They do have several advantages like lack of systemic side effects, ease of application without dose titration. Hence, they may be useful in localised neuropathic pain.

\subsection{Topical Capsaicin}

Capsaicin is the pungent component of chilli peppers. The mechanism of action is thought to lie in its ability to selectively stimulate unmyelinated C-fibres to cause the depletion of substance P and other neurotransmitters [53]. It causes a localised desensitisation after a period of initial irritation [54]. A 2013 Cochrane review found that highconcentration capsaicin (8\%) was better than control [55]. Although the number of people who obtained benefit over control is not large, they did have additional improvements in sleep, depression and overall quality of life, which make it comparable to other anti-neuropathic therapies.

\subsection{Opioids}

The role of opioids in managing chronic pain is controversial. There are concerns about side effects, long-term efficacy, functional outcomes and the potential for drug abuse and addiction [56]. However, it is recognised among pain specialists that a subgroup of patients may benefit from long-term therapy. This requires careful dose titration and monitoring under specialist care [57]. Newer opioids with multimodal action like tramadol and tapentadol have fewer side effects, low potential for drug abuse and possible anti-neuropathic effect by targeting other receptors [58]. Tramadol is a weak opioid agonist and a serotonin and norepinephrine reuptake inhibitor. A Cochrane review looked at five randomised controlled trials and concluded that tramadol is effective treatment for neuropathic pain [59]. 
Tapentadol is relatively newer and is similar to tramadol in its dual mechanism of action but only has weak effects on the reuptake of serotonin [60]. Unlike tramadol, tapentadol is not a pro-drug and has no active metabolites, making its pharmacokinetics more predictable with less potential for drug interactions [61]. The studies to date have been of inconclusive clinical significance due to high drop out rates and modest difference between interventions in efficacy outcomes [62].

\subsection{Botulinum Toxin A}

Botulinum neurotoxin is derived from Clostridum botulinum. It acts by inhibiting acetylcholine neurotransmitter release at presynaptic terminals, causing neuromuscular blockade [63]. However, there are several subtypes which are antigenically different. Subtype A is suggested to inhibit the release of local nociceptive neuropeptides, which may play a role in suppressing peripheral sensitisation [64]. While several double-blinded, placebo-controlled studies have suggested that Botulinum Toxin A has antinociceptive effects in neuropathic pain [65], the overall evidence shows that its efficacy is mainly limited to post-herpetic neuralgia, trigeminal neuralgia, post-traumatic neuralgia and possibly diabetic neuropathy [66].

Over the past decade, meta-analyses of these drugs have resulted in numerous treatment algorithms for neuropathic pain based on randomised clinical trials [47]. While most of them are generally fit for purpose, there are discrepant recommendations due to publication bias. The Neuropathic Pain Special Interest Group (NeuPSIG) published updated recommendations in 2015 based on a systematic review, which incorporated large, unpublished data and recent high quality clinical trials [50]. A more robust system of recommending drugs was used. The result of this analysis is that TCAs, SNRI antidepressants duloxetine and venlafaxine, and gabapentinoids are proposed as first-line therapy. Tramadol, lidocaine patches and high concentration capsaicin patches having weaker evidence and are proposed as second-line therapy. Strong opioids and botulinum toxin A have weak recommendations and therefore reserved as thirdline therapy. Key differences with previous algorithms are: downgrading of lidocaine patch to second-line, downgrading of strong opioids to third-line, and inclusion of high-concentration capsaicin patches for the first time in the algorithm.

\section{REGIONAL NERVE BLOCKADE}

Historically, epidural analgesia has been considered as the 'gold-standard' for post-thoracotomy pain management. Its drawbacks are not insignificant, which can include systemic hypotension, risk of spinal cord injury and a relatively high failure rate. Recent advances in regional techniques have seen the emergence of viable alternatives such as paravertebral blocks and intercostal blocks. A recently updated meta-analysis comparing paravertebral and epidural blockade revealed that in both techniques there was no statistically significant pain scores or morphine consumption in the first 24 hours postoperatively [67]. In fact, paravertebral blockade had fewer side effects such as urinary retention, nausea, vomiting and hypotension. There is a definite shift in trend away from epidural analgesia for post-thoracotomy pain. Added to the mix are novel techniques such as serratus anterior plane block, which has only recently been described in literature [68].

Despite the clear benefit of regional nerve blockade in acute pain, its use in reducing chronic pain is less certain. Studies have yielded conflicting results, with larger trials failing to demonstrate an effect. A meta-analysis of six randomised controlled trials looking into the role thoracic epidural analgesia showed that there was no significant difference at 6 months [69]. This might not be surprising considering that other nerves outside the spinal cord such as phrenic, vagus and brachial plexus nerves are involved in the nociceptive pathway [70].

Pharmacological agents used in regional nerve blockade are often a combination of local anaesthetic drugs and opioids. Levo-bupivacaine and ropivacaine are commonly used. These are weak bases, which temporarily block sodium channels along neurons and disrupting electrical transmission along the nociceptive pathway. The addition of opioids appears to enhance its analgesic effect. A double-blind, randomised controlled trial demonstrated that $0.15 \%$ ropivacaine with $5 \mathrm{mcg} / \mathrm{ml}$ fentanyl was significantly better than plain $0.2 \%$ ropivacaine [71].

\section{CONCLUSION}

In summary, studies looking into alternative adjunct therapy to opioid analgesia have been small and underpowered. Clinical trials looking into ketamine and gabapentinoids do appear to be effective for acute pain but concerns regarding side effects have limited their widespread use. Furthermore, this result has not translated into success in pre-emptive treatment of chronic post-thoracotomy pain. While there may be sporadic reports of positive trials in the literature, none 
has been adequately powered to detect a statistically significant difference. At best, there is some suggestion that gabapentinoids may be useful in managing PTPS if it is continued as long-term therapy, but there are no definitive studies to suggest a role for a single add-on pharmacological agent that can reduce PTPS. What is also striking is the lack of research into pharmacological agents for the long-term treatment of PTPS [24]. There is generally a paucity of clinical trials, which specifically evaluate neuropathic pain in post-thoracotomy patients. Often this is due to the sizeable number of cancer patients in this group who are included in larger studies looking at palliative pain management [72]. More research and clinical trials are required in this area. For the time being, conventional strategies involving regional local anaesthetic agents with systemic opioids remain the mainstay of treatment for acute postthoracotomy pain. Close follow up is important for diagnosing and managing post-thoracotomy patients with PTPS with the use of established antineuropathic agents.

\section{CONFLICT OF INTEREST}

The authors confirm that this article content has no conflict of interest.

\section{ACKNOWLEDGEMENTS}

$\mathrm{KV}$ was responsible for the conception, organisation and revision of the article.

JC was responsible for preparing the draft manuscript.

\section{REFERENCES}

[1] Gerner P. Postthoracotomy pain management problems. Anesthesiol Clin 2008; 26(2): 355-367, vii. [http://dx.doi.org/10.1016/j.anclin.2008.01.007] [PMID: 18456219]

[2] Sabanathan S, Eng J, Mearns AJ. Alterations in respiratory mechanics following thoracotomy. J R Coll Surg Edinb 1990; 35(3): 144-50. [PMID: 2203902]

[3] Reddi D. Preventing chronic postoperative pain. Anaesthesia 2016; 71(Suppl. 1): 64-71. [http://dx.doi.org/10.1111/anae.13306] [PMID: 26620149]

[4] Conacher ID. Therapists and therapies for post-thoracotomy neuralgia. Pain 1992; 48(3): 409-12. [http://dx.doi.org/10.1016/0304-3959(92)90093-Q] [PMID: 1594264]

[5] Guay DR. Adjunctive agents in the management of chronic pain. Pharmacotherapy 2001; 21(9): 1070-81. [Review]. [http://dx.doi.org/10.1592/phco.21.13.1070.34622] [PMID: 11560197]

[6] Garimella V, Cellini C. Postoperative pain control. Clin Colon Rectal Surg 2013; 26(3): 191-6. [http://dx.doi.org/10.1055/s-0033-1351138] [PMID: 24436674]

[7] Gottschalk A, Cohen SP, Yang S, Ochroch EA. Preventing and treating after thoracic surgery. Anesthesiology 2006; 104(3): 594-600. [http://dx.doi.org/10.1097/00000542-200603000-00027]

[8] Barak M, Ziser A, Katz Y. Thoracic epidural local anesthetics are ineffective in alleviating post-thoracotomy ipsilateral shoulder pain. J Cardiothorac Vasc Anesth 2004; 18(4): 458-60. [http://dx.doi.org/10.1053/j.jvca.2004.05.025] [PMID: 15365928]

[9] Mathews TJ, Churchhouse AM, Housden T, Dunning J. Does adding ketamine to morphine patient-controlled analgesia safely improve postthoracotomy pain? Interact Cardiovasc Thorac Surg 2012; 14(2): 194-9. [http://dx.doi.org/10.1093/icvts/ivr081] [PMID: 22159259]

[10] Zakkar M, Frazer S, Hunt I. Is there a role for gabapentin in preventing or treating pain following thoracic surgery? Interact Cardiovasc Thorac Surg 2013; 17(4): 716-9. [http://dx.doi.org/10.1093/icvts/ivt301] [PMID: 23832920]

[11] Kinney MA, Hooten WM, Cassivi SD, et al. Chronic postthoracotomy pain and health-related quality of life. Ann Thorac Surg 2012; 93(4): 1242-7. [http://dx.doi.org/10.1016/j.athoracsur.2012.01.031] [PMID: 22397986]

[12] Wildgaard K, Ravn J, Kehlet H. Chronic post-thoracotomy pain: a critical review of pathogenic mechanisms and strategies for prevention. Eur J Cardiothorac Surg 2009; 36(1): 170-80. [http://dx.doi.org/10.1016/j.ejcts.2009.02.005] [PMID: 19307137]

[13] Peng Z, Li H, Zhang C, Qian X, Feng Z, Zhu S. A retrospective study of chronic post-surgical pain following thoracic surgery: prevalence, risk factors, incidence of neuropathic component, and impact on qualify of life. PLoS One 2014; 9 (2): e90014. [http://dx.doi.org/10.1371/journal.pone.0090014] [PMID: 24587187]

[14] Miyazaki T, Sakai T, Yamasaki N, et al. Chest tube insertion is one important factor leading to intercostal nerve impairment in thoracic surgery. Gen Thorac Cardiovasc Surg 2014; 62(1): 58-63.

[15] Treede RD, Jensen TS, Campbell JN, et al. Neuropathic pain: redefinition and a grading system for clinical and research purposes. Neurology 
2008; 70(18): 1630-5

[http://dx.doi.org/10.1212/01.wnl.0000282763.29778.59] [PMID: 18003941]

[16] Cohen SP, Mao J. Neuropathic pain: mechanisms and their clinical implications. BMJ 2014; $348:$ f7656. [http://dx.doi.org/10.1136/bmj.f7656] [PMID: 24500412]

[17] Wall PD, Devor M. Sensory afferent impulses originate from dorsal root ganglia as well as from the periphery in normal and nerve injured rats. Pain 1983; 17(4): 321-39. [http://dx.doi.org/10.1016/0304-3959(83)90164-1] [PMID: 6664680]

[18] Devor M, Keller CH, Deerinck TJ, Levinson SR, Ellisman MH. Na+ channel accumulation on axolemma of afferent endings in nerve end neuromas in Apteronotus. Neurosci Lett 1989; 102(2-3): 149-54 [http://dx.doi.org/10.1016/0304-3940(89)90070-0] [PMID: 2554205]

[19] Campbell JN, Meyer RA. Mechanisms of neuropathic pain. Neuron 2006; 52(1): 77-92. [http://dx.doi.org/10.1016/j.neuron.2006.09.021] [PMID: 17015228]

[20] Lee KY, Prescott SA. Chloride dysregulation and inhibitory receptor blockade yield equivalent disinhibition of spinal neurons yet are differentially reversed by carbonic anhydrase blockade. Pain 2015; 156(12): 2431-7. [http://dx.doi.org/10.1097/j.pain.0000000000000301] [PMID: 26186265]

[21] Searle RD, Simpson MP, Simpson KH, Milton R, Bennett MI. Can chronic neuropathic pain following thoracic surgery be predicted during the postoperative period? Interact Cardiovasc Thorac Surg 2009; 9(6): 999-1002. [http://dx.doi.org/10.1510/icvts.2009.216887] [PMID: 19767301]

[22] Clarke H, Bonin RP, Orser BA, Englesakis M, Wijeysundera DN, Katz J. The prevention of chronic postsurgical pain using gabapentin and pregabalin: a combined systematic review and meta-analysis. Anesth Analg 2012; 115(2): 428-42. [http://dx.doi.org/10.1213/ANE.0b013e318249d36e] [PMID: 22415535]

[23] Grosen K, Drewes AM, Højsgaard A, Pfeiffer-Jensen M, Hjortdal VE, Pilegaard HK. Perioperative gabapentin for the prevention of persistent pain after thoracotomy: a randomized controlled trial. Eur J Cardiothorac Surg 2014; 46(1): 76-85. [http://dx.doi.org/10.1093/ejcts/ezu032] [PMID: 24574444]

[24] Sihoe AD, Lee TW, Wan IY, Thung KH, Yim AP. The use of gabapentin for post-operative and post-traumatic pain in thoracic surgery patients. Eur J Cardiothorac Surg 2006; 29(5): 795-9. [http://dx.doi.org/10.1016/j.ejcts.2006.02.020] [PMID: 16581258]

[25] No authors listed. Why pregabalin? Drug Ther Bull 2010; 48(6): 61. [http://dx.doi.org/10.1136/dtb.2010.04.0029] [PMID: 20530026]

[26] Brulotte V, Ruel MM, Lafontaine E, Chouinard P, Girard F. Impact of pregabalin on the occurrence of postthoracotomy pain syndrome: a randomized trial. Reg Anesth Pain Med 2015; 40(3): 262-9. [http://dx.doi.org/10.1097/AAP.0000000000000241] [PMID: 25899956]

[27] Mishra A, Nar AS, Bawa A, Kaur G, Bawa S, Mishra S. Pregabalin in chronic post-thoracotomy pain. J Clin Diagn Res 2013; 7(8): 1659-61. [PMID: 24086867]

[28] Visser E, Schug SA. The role of ketamine in pain management. Biomed Pharmacother 2006; 60(7): $341-8$. [http://dx.doi.org/10.1016/j.biopha.2006.06.021] [PMID: 16854557]

[29] Carstensen M, Møller AM. Adding ketamine to morphine for intravenous patient-controlled analgesia for acute postoperative pain: a qualitative review of randomized trials. Br J Anaesth 2010; 104(4): 401-6. [http://dx.doi.org/10.1093/bja/aeq041] [PMID: 20207747]

[30] Tena B, Gomar C, Rios J. Perioperative epidural or intravenous ketamine does not improve the effectiveness of thoracic epidural analgesia for acute and chronic pain after thoracotomy. Clin J Pain 2014; 30(6): 490-500. [http://dx.doi.org/10.1097/AJP.0000000000000005] [PMID: 24281290]

[31] Hu J, Liao Q, Zhang F, Tong J, Ouyang W. Chronic postthoracotomy pain and perioperative ketamine infusion. J Pain Palliat Care Pharmacother $2014 ; 28(2): 117-21$. [http://dx.doi.org/10.3109/15360288.2014.908992] [PMID: 24799159]

[32] Joseph C, Gaillat F, Duponq R, et al. Is there any benefit to adding intravenous ketamine to patient-controlled epidural analgesia after thoracic surgery? A randomized double-blind study. Eur J Cardiothorac Surg 2012; 42(4): e58-65. [http://dx.doi.org/10.1093/ejcts/ezs398] [PMID: 22790008]

[33] Mendola C, Cammarota G, Netto R, et al. S+ -ketamine for control of perioperative pain and prevention of post thoracotomy pain syndrome: a randomized, double-blind study. Minerva Anestesiol 2012; 78(7): 757-66. [PMID: 22441361]

[34] Comez M, Celik M, Dostbil A, et al. The effect of pre-emptive intravenous Dexketoprofen + thoracal epidural analgesia on the chronic postthoracotomy pain. Int J Clin Exp Med 2015; 8(5): 8101-7. [PMID: 26221376]

[35] McCrory C, Fitzgerald D. Spinal prostaglandin formation and pain perception following thoracotomy: a role for cyclooxygenase-2. Chest 2004; 125(4): 1321-7. [http://dx.doi.org/10.1378/chest.125.4.1321] [PMID: 15078741] 
[36] Guidance: Cox-2 selective inhibitors and non-steroidal anti-inflammatory drugs (NSAIDS): Cardiovascular safety. Available from: www.gov.uk/government/publications/cox-2-selective-inhibitors-and-non-steroidal-anti-inflammatory-drugs-nsaids-cardiovascular-safety/

[37] Ren C, Zhang X, Liu Z, Li C, Zhang Z, Qi F. Effect of intraoperative and postoperative infusion of dexmedetomidine on the quality of postoperative analgesia in highly nicotine-dependent patients after thoracic surgery: A CONSORT-prospective, randomized, controlled trial. Medicine (Baltimore) 2015; 94(32): e1329. [http://dx.doi.org/10.1097/MD.0000000000001329] [PMID: 26266376]

[38] Kogler J. The analgesic effect of magnesium sulfate in patients undergoing thoracotomy. Acta Clin Croat 2009; 48(1): 19-26. [PMID: 19623867]

[39] Ozcan PE, Tugrul S, Senturk NM, et al. Role of magnesium sulfate in postoperative pain management for patients undergoing thoracotomy. J Cardiothorac Vasc Anesth 2007; 21(6): 827-31. [http://dx.doi.org/10.1053/j.jvca.2006.11.013] [PMID: 18068060]

[40] Song JG, Shin JW, Lee EH, et al. Incidence of post-thoracotomy pain: a comparison between total intravenous anaesthesia and inhalation anaesthesia. Eur J Cardiothorac Surg 2012; 41(5): 1078-82. [http://dx.doi.org/10.1093/ejcts/ezr133] [PMID: 22290901]

[41] Flood P, Sonner JM, Gong D, Coates KM. Isoflurane hyperalgesia is modulated by nicotinic inhibition. Anesthesiology 2002; 97(1): 192-8. [http://dx.doi.org/10.1097/00000542-200207000-00027] [PMID: 12131122]

[42] Salengros JC, Huybrechts I, Ducart A, et al. Different anesthetic techniques associated with different incidences of chronic post-thoracotomy pain: low-dose remifentanil plus presurgical epidural analgesia is preferable to high-dose remifentanil with postsurgical epidural analgesia. $\mathbf{J}$ Cardiothorac Vasc Anesth 2010; 24(4): 608-16.

[http://dx.doi.org/10.1053/j.jvca.2009.10.006] [PMID: 20005744]

[43] Yalcin I, Choucair-Jaafar N, Benbouzid M, et al. beta(2)-adrenoceptors are critical for antidepressant treatment of neuropathic pain. Ann Neurol 2009; 65(2): 218-25. a [http://dx.doi.org/10.1002/ana.21542] [PMID: 19259968]

[44] Cok OY, Eker HE, Yalcin I, Barrot M, Aribogan A. Is there a place for beta-mimetics in clinical management of neuropathic pain? Salbutamol therapy in six cases. Anesthesiology 2010; 112(5): 1276-9. [http://dx.doi.org/10.1097/ALN.0b013e3181d40399] [PMID: 20395826]

[45] Salvat E, Schweitzer B, Massard G, et al. Effects of $\beta 2$ agonists on post-thoracotomy pain incidence. Eur J Pain 2015; 19(10): 1428-36. [http://dx.doi.org/10.1002/ejp.673] [PMID: 25766791]

[46] Attal N, Fermanian C, Fermanian J, Lanteri-Minet M, Alchaar H, Bouhassira D. Neuropathic pain: are there distinct subtypes depending on the aetiology or anatomical lesion? Pain 2008; 138(2): 343-53. [http://dx.doi.org/10.1016/j.pain.2008.01.006] [PMID: 18289791]

[47] Finnerup NB, Sindrup SH, Jensen TS. The evidence for pharmacological treatment of neuropathic pain. Pain 2010; 150(3): 573-81. [http://dx.doi.org/10.1016/j.pain.2010.06.019] [PMID: 20705215]

[48] Watson CP, Evans RJ, Reed K, Merskey H, Goldsmith L, Warsh J. Amitriptyline versus placebo in postherpetic neuralgia. Neurology 1982; 32(6): 671-3.

[http://dx.doi.org/10.1212/WNL.32.6.671] [PMID: 6283422]

[49] Max MB, Lynch SA, Muir J, Shoaf SE, Smoller B, Dubner R. Effects of desipramine, amitriptyline, and fluoxetine on pain in diabetic neuropathy. N Engl J Med 1992; 326(19): 1250-6. [http://dx.doi.org/10.1056/NEJM199205073261904] [PMID: 1560801]

[50] Finnerup NB, Attal N, Haroutounian S, et al. Pharmacotherapy for neuropathic pain in adults: a systematic review and meta-analysis. Lancet Neurol 2015; 14(2): 162-73.

[http://dx.doi.org/10.1016/S1474-4422(14)70251-0] [PMID: 25575710]

[51] Perret D, Luo ZD. Targeting voltage-gated calcium channels for neuropathic pain management. Neurotherapeutics 2009; 6(4): 679-92. [http://dx.doi.org/10.1016/j.nurt.2009.07.006] [PMID: 19789072]

[52] Derry S, Wiffen PJ, Moore RA, Quinlan J. Topical lidocaine for neuropathic pain in adults. Cochrane Database Syst Rev 2014; (7): CD010958.

[PMID: 25058164]

[53] Roberts C, Morgan L, Hall K, et al. A case study in the use of capsaicin in the treatment of neuropathic chest wall pain and post thoracotomy intercostal neuralgia. Open J Anesthesiol 2012; 2: 99-101. [http://dx.doi.org/10.4236/ojanes.2012.24023]

[54] Moore RA, et al. Topical analgesics for acute and chronic pain in adults. Cochrane Database Syst Rev 2010; (7): [http://dx.doi.org/10.1002/14651858.CD008609]

[55] Derry S, et al. Topical capsaicin (high concentration) for chronic neuropathic pain in adults. Cochrane Database Syst Rev 2013. [http://dx.doi.org/10.1002/14651858.CD007393.pub3]

[56] Rosenblum A, Marsch LA, Joseph H, Portenoy RK. Opioids and the treatment of chronic pain: controversies, current status, and future directions. Exp Clin Psychopharmacol 2008; 16(5): 405-16. [http://dx.doi.org/10.1037/a0013628] [PMID: 18837637] 
[57] Trescot AM, Boswell MV, Atluri SL, et al. Opioid guidelines in the management of chronic non-cancer pain. Pain Physician 2006; 9(1): 1-39. [PMID: 16700278]

[58] Mattia C, Coluzzi F. Tramadol: a wonder drug for the treatment of chronic pain? Int J Clin Rheumatol 2010; (1): 1-4. [http://dx.doi.org/10.2217/ijr.09.71]

[59] Duehmke RM, Hollingshead J, Cornblath DR. Tramadol for neuropathic pain. Cochrane Database Syst Rev 2006; (3): [http://dx.doi.org/10.1002/14651858.CD003726.pub3]

[60] Singh DR, Nag K, Shetti AN, Krishnaveni N. Tapentadol hydrochloride: A novel analgesic. Saudi J Anaesth 2013; 7(3): $322-6$. [http://dx.doi.org/10.4103/1658-354X.115319] [PMID: 24015138]

[61] Raffa RB, Buschmann H, Christoph T, et al. Mechanistic and functional differentiation of tapentadol and tramadol. Expert Opin Pharmacother 2012; 13(10): 1437-49. [http://dx.doi.org/10.1517/14656566.2012.696097] [PMID: 22698264]

[62] Santos J, Alarcão J, Fareleira F, et al. Tapentadol for chronic musculoskeletal pain in adults. Cochrane Database Syst Rev 2015; (5): [http://dx.doi.org/10.1002/14651858.CD009923.pub2]

[63] Kao I, Drachman DB, Price DL. Botulinum toxin: mechanism of presynaptic blockade. Science 1976; 193(4259): $1256-8$. [http://dx.doi.org/10.1126/science.785600] [PMID: 785600]

[64] Aoki KR. Future aspects of botulinum neurotoxins. J Neural Transm (Vienna) 2008; 115(4): 567-73. [http://dx.doi.org/10.1007/s00702-007-0758-9] [PMID: 17557128]

[65] Jeynes LC, Gauci CA. Evidence for the use of botulinum toxin in the chronic pain settinga review of the literature. Pain Pract 2008; 8(4): 269-76. [http://dx.doi.org/10.1111/j.1533-2500.2008.00202.x] [PMID: 18503628]

[66] Oh H-M, Chung ME. Botulinum toxin for neuropathic pain: A review of the literature. Toxins (Basel) 2015; 7(8): $3127-54$. [http://dx.doi.org/10.3390/toxins7083127] [PMID: 26287242]

[67] Ding X, Jin S, Niu X, et al. Landoni G. A comparison of the analgesia efficacy and side effects of paravertebral compared with epidural blockade for thoracotomy: an updated meta-analysis. PLoS One 2014; 9(5): e96233. [http://dx.doi.org/http://dx.doi.org/10.1371/journal.pone.0096233]

[68] Madabushi R, Tewari S, Gautam SK, Agarwal A, Agarwal A. Serratus anterior plane block: a new analgesic technique for post-thoracotomy pain. Pain Physician 2015; 18(3): E421-4. [PMID: 26000690]

[69] Bong CL, Samuel M, Ng JM, Ip-Yam C. Effects of preemptive epidural analgesia on post-thoracotomy pain. J Cardiothorac Vasc Anesth 2005; 19(6): 786-93. [http://dx.doi.org/10.1053/j.jvca.2005.08.012] [PMID: 16326309]

[70] Karmakar MK, Ho AM. Postthoracotomy pain syndrome. Thorac Surg Clin 2004; 14(3): 345-52. [http://dx.doi.org/10.1016/S1547-4127(04)00022-2] [PMID: 15382766]

[71] Macias A, Monedero P, Adame M, Torre W, Fidalgo I, Hidalgo F. A randomized, double-blinded comparison of thoracic epidural ropivacaine, ropivacaine/fentanyl, or bupivacaine/fentanyl for postthoracotomy analgesia. Anesth Analg 2002; 95(5): 1344-50. [http://dx.doi.org/10.1097/00000539-200211000-00046] [PMID: 12401624]

[72] Garzón-Rodríguez C, Casals Merchan M, Calsina-Berna A, López-Rómboli E, Porta-Sales J. Lidocaine 5\% patches as an effective short-term co-analgesic in cancer pain. Preliminary results. Support Care Cancer 2013; 21(11): 3153-8. [http://dx.doi.org/10.1007/s00520-013-1948-7] [PMID: 24000041]

(C) Ee Chin and Valchanov; Licensee Bentham Open

This is an open access article licensed under the terms of the Creative Commons Attribution-Non-Commercial 4.0 International Public License (CC BY-NC 4.0) (https://creativecommons.org/licenses/by-nc/4.0/legalcode), which permits unrestricted, non-commercial use, distribution and reproduction in any medium, provided the work is properly cited. 